BMJ Open

Sport \&

Exercise

Medicine

\section{Concussion guideline implementation perceptions and experiences among parents of community-level Australian Football junior players}

To cite: White PE, RegisterMihalik J, Donaldson A, et al. Concussion guideline implementation perceptions and experiences among parents of community-level Australian Football junior players. BMJ Open Sport Exerc Med 2017;3:e000215. doi:10.1136/bmjsem-2016000215

Accepted 13 March 2017

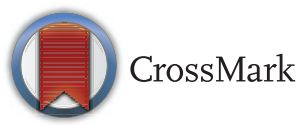

${ }^{1}$ Australian Collaboration for Research into Injury in Sport and Its Prevention,

Federation University Australia, Ballarat, Victoria, Australia

${ }^{2}$ University of North Carolina at Chapel Hill, Chapel Hill, North Carolina, USA

${ }^{3}$ School of Physiotherapy, University of Otago, Dunedin, New Zealand

Correspondence to Professor Caroline F Finch; c.finch@federation.edu.au

\section{ABSTRACT}

Background/aim Concussion guidelines exist for multiple community sports. Parents are key stakeholders in guideline implementation and in appropriate responses following concussive injury. The purpose of this qualitative investigation was to understand how parents of community-level Australian Football (AF) players experience and perceive concussion guidelines in order to inform the design and implementation of concussion guidelines in community sport.

Methods A cross-sectional qualitative approach was adopted to allow for an open and detailed exploration of the views of parents of junior community AF players (ie, those aged $<16$ years) regarding concussion guidelines of the AF League (AFL) - the national governing body for AF. Participants were 15 parents of junior community AF players from two clubs affiliated with a large regional community AF League.

Results The key experiences and perceptions of the parents included appreciation that the guidelines outlined the postconcussion process that should be followed, desires for better understanding of the guidelines by general practitioners (ie, medical doctors) who care for children with concussion, having more readily available information for parents and receiving more formal policy guiding timing of return-toparticipation following concussion. Difficulties with the guidelines not addressing delayed presentations of concussion were also frequently mentioned.

Conclusions Parents are key stakeholders in concussion prevention and care in community sport. As such, their input should be considered when developing guidelines and resources for community sport. Furthermore, concussion information should be made available to parents in an easily accessible and community-friendly form.

\section{INTRODUCTION}

Targeted guidelines exist in various sports to encourage an appropriate response following concussion among participants. ${ }^{1-4}$ These guidelines include appropriate steps to follow should someone sustain a suspected concussion and have been adapted for many types of

\section{What are the findings?}

- Parents are concerned about medical doctors knowledge and management of concussion.

- Systematically available concussion educational material and guideline information is important to parents.

- Parents desire clearer information on timing of return-to-participation.

community sports, including Australian Football (AF). ${ }^{3}{ }^{4}$ Stakeholder understanding and implementation of these guidelines are key to achieving the intended outcomes of appropriate injury recognition and management, and ultimately improved safety following concussion. Parents are a primary stakeholder to consider in concussion guideline development and implementation in the community sport setting. Furthermore, a recent study among parents of AF players suggested that those with concussion-related training had better knowledge than those with no training or background. ${ }^{5}$ Parental involvement in this setting is high and parents are the primary care-seekers for their children following concussion. ${ }^{6}$

Despite the role of parents in the implementation and sustainability of concussion guidelines, no studies have evaluated parents' perceptions of these guidelines and their perceived advantages and disadvantages. The purpose of this qualitative investigation was to understand how parents of community-level $\mathrm{AF}$ players experience and perceive concussion guidelines in order to inform the design and implementation of concussion guidelines in community sport.

\section{METHODS}

A qualitative approach was adopted to allow for an open and detailed exploration of parents of junior community AF players' (ie, 
Table 1 Parent-stated advantages and disadvantages to implementing the concussion guidelines in community Australian Football

\section{Subthemes}

Example quotes

Provides a starting point for diagnosing and managing
concussion

\section{Advantages}

A resource to show parents when they question the decision to remove a child from play following a concussion.

'Well ... well, if in doubt, you'd ... follow the guidelines'.

'That's ... why I love this ... document. Because I can go back to that and say "Righto, sit down and read this and then come back and tell me that your twelve year old should be right out there right now"'.

\section{Disadvantages}

Differences in the interpretation of the guidelines

Difficulty diagnosing concussion in children, particularly in relation to cases that are not clear cut (ie, player does not lose consciousness) or when the symptoms are not obvious

Do not allow for individual differences in the way people respond to concussion, particularly in relation to the potential for a delay in the onset of symptoms
'That's right. The interpretation of it. Because some people interpret ... interpret things differently than others and basically look at that and say, "Well, hang on. They don't say that in the guidelines compared to what you're saying. Or what the doctor said". So, there's that circle of ... that goes around that you get one, two, three, maybe four different stories'.

'When it's black and white and there is a concussion, it's easy. But when it's borderline, there is no concussion and there may be headaches or slight dizziness. That's the grey areas that are hard to address'.

'Well, they're only guidelines and ... apart from concussion, every injury is different Every person is different. So, how can you make a policy that relates to everyone and the injury? It's all different'. those aged $<16$ years) views on the AF League's (AFLthe national governing body for $\mathrm{AF}$ ) concussion guidelines. A convenience sample of 15 parents of junior male community AF players from two clubs affiliated with a large regional community AF league was recruited. Being a parent of a child who was playing AF in the current season was the only inclusion criterion. The groups included both male and female parents from two clubs affiliated with a large regional community AF league. These clubs (and parents) were the only ones who responded to an invitation to parents to participate in the study, circulated through the AF league's networks. At the time of the study, the AF league was a male league, so all focus participants were parents of boys. Two focus groups (group $1 \mathrm{n}=9$, group $2 \mathrm{n}=6$ ) were conducted. The focus groups were conducted at the respective club's clubrooms, and the parents participated in a focus group with other parents from their child's club only.

The parents were encouraged to access the 2011 AFL concussion guidelines one week before the focus groups. They were also provided with a hard copy of these guidelines at the time of the group. Focus group discussions were conducted before the end of the 2012 playing season. They were led by author $\mathrm{AD}$, an experienced focus group facilitator, with assistance from the lead author. Each discussion lasted approximately 1 hour and took place at the AF club's clubrooms on a midweek evening.
At the beginning of each focus group, parents were provided with a written scenario and some follow-up questions. They were asked to write dot point responses to the questions to stimulate their thinking around some of the issues that would then be discussed. The remainder of each focus group followed a semistructured script. Group discussions were audio-recorded and transcribed verbatim. Transcripts were checked for accuracy against the audio-recordings and corrected for anomalies. The transcripts were read and re-read, and hand-coded by two authors (PW and JR-M) using thematic analysis as a framework. Transcripts were coded independently and discrepancies were resolved through discussion. The coding scheme was designed to extract major and subthemes relating to the focus group discussion themes of advantages and disadvantages to implementing the guidelines, facilitators and barriers to using the guidelines, as well as ways to improve the guidelines and deliver them more effectively.

The study was approved by the Monash University Human Research Ethics Committee. Participants were given a plain language statement about the research project and provided written, informed consent prior to study participation.

\section{RESULTS}

Approximately one-third of the parents were also sports trainers who provided field-side first aid support. These 
Table 2 Parent-stated facilitators and barriers to appropriate use of the concussion guidelines in community Australian Football

\section{Subthemes}

Example quotes

\section{Facilitators}

Having an understanding of what the children are like normally

If the concussive incident was observed by the person making the decision

Guidelines enforced at the professional (Australian Football League) and state governing (Victorian Football League) levels

Enforce a clear club policy that supports best practices for concussion management and enforcement of the guidelines

Stakeholder (players/parents/umpires/ coaches) education and knowledge
'It helps if you know the kid I think'.

'I think it helps you judge the situation better if you saw the incident'.

'I think you'll find that the ... how the leagues will work is that basically they'll follow the AFL direction. ... but certainly, yeah, I don't think you'll find the the leagues moving until the AFL moves'.

'Once you know about it and you know that the club's going to enforce it. If you have an episode like this that you're going to have a week off or you may need a couple of weeks off. I think that would hurt them [the players] less because they wouldn't maybe put up as bigger fight as they do'.

'Yeah, I think let's just say parents don't know enough about it really. I think it's all sort of still a grey area for them... The under eighteens and all the senior boys do it. They come off you know, blood ... they come straight off the ground. Well, why can't they get that into their noggins? Into their ... you know, why can't they think the same way [about concussion]? That's why I think they [the players] need to be a bit more informed, yeah'.

\section{Barriers}

Players wanting to play at all costs

'Yeah. If they generally just sort of you know, "I don't care.

I'm going back out there"'.

Players refusing to be taken to medical provider for care/evaluation

'But I felt bad. I could not get him into emergency that Saturday afternoon, he would not go'.

Lack of support from parents due to their lack of knowledge about the seriousness of concussion

Inconsistency in medical care due to difference in practices or lack of knowledge (eg, general practitioners or emergency department doctors)

'But a lot of the time I must admit, like especially out in the bush, parents don't give two hoots about it. Let him back on you know? You'll get that every day of the week'.

'Well, that's one of my question marks. Because ... I'm not convinced that they all would have the same abilities of assessing a concussion. And ... and they might not. You know, because there's a more extensive SCAT isn't there? ... And yeah, I'm not convinced that that ... they would all be able to do that well and even know of its existence in some cases'.

Concussive incidents or symptoms that occur outside of direct contact of the team/club (eg, delayed concussion presentation; playing in a different league/sport)

'Whereas reading this, you can be concussed but especially with delayed, you don't even have to cop a knock to the head. You could ... cop a knock in a game where you're spinning around and you could ... it's says in here, whiplash. And no one will pick on that during the game. And yet your son will ... go home and then have the delayed reaction and no one's picked up on it'.

Cost/time associated with visiting the medical provider
'Yeah. l'd say cost and time. People are flat out these days aren't they? Like you know, trying to find time to make an appointment, get in. You know, trying to get into your GP's almost impossible'. 
Table 3 Ways to improve and delivery the guidelines more effectively

Subthemes

Example quotes

Improvement considerations

Have a specific policy for a delayed return to play (eg, 2 weeks post injury at a minimum)

Some additional information specifically for parents of junior players and for that to be included on the flow chart as well

Insisting on detailed record keeping by teams and medical personnel

More parent specific information (written/directed) about concussion

'Yeah, just ....like we've done. Just ... they should have them ... a week or two weeks off. Because a lot like I said, a lot of sickness can come out a week later'.

"'Even though I think it's probably not specific enough to the under 18 cohort'.

'Well the other thing ... it's like we've got a diagnosis there's the next thing that doesn't apply to juniors because you just make that on the footnote if you have to'.

'And I guess too, given that it's new, I wonder whether there's some value in getting some data off the trainers ... around ... like actually evaluating its use and ... and when it's worked and when it hasn't worked and things like that'.

'On the top of the flowchart or ... some advice to parents to say what the incidents is in ... concussions in Australian Rules'.

\section{Delivery considerations}

Information provided at registration and/or code of conduct

'So parents really at, even if at. .the sign up you know? At the start of each year where you sign your. . Registration. Maybe it should be-___ I think too as part of the code of conduct. If people. if parents are aware of it ... if most people if you know the parameters that you work in, they adhere to it'.

An expert/medical provider to assess what is happening in the club and provide advice

'There's also the opportunity to get the professionals ... to come in and you know, look at what ... you've got set within your own club and advise you on you know, what you should be doing and they can come in assist you and I don't think many people know .

Pocket cards with basic guidelines available 'Yep and I think even this pocket SCAT could be laminated'.

Video about the guidelines and concussion that is easily available

'People are pretty slack with reading things. Like, I mean you take for instance, you get a new DVD or a TV, does anyone read the manuals and know really? It's the same sort of scenario'.

Posters in the club

'So, clearly on display. But if people see it and you keep ... it's like branding. .. and advertising. The more people see it the more people will be aware of it. And adhere to it'.

Easily accessible on the web

'But it's the sort of thing that'd be actually really good to have on our website'. sports trainers, who are usually volunteers with a sports team, undergo several hours of accredited sports first aid training. Thus, it is likely that parents who are also sports trainers would be more knowledgeable about, and more interested and experienced in dealing with, concussion than others. While the perceptions and experiences of people who are both parents and sports trainers may be different to those of people who are a parent only, including parents who are sports trainers in the current sample reflects the dual roles of many parents in community $\mathrm{AF}$.

Table 1 outlines the subthemes identified for the advantages and disadvantages. Table 2 outlines the subthemes identified for facilitators and barriers.
Table 3 outlines the subthemes identified to improve and deliver the guidelines.

\section{DISCUSSION}

This study highlights the experiences and perceptions of parents of junior community AF players in the implementation and use of the AF concussion guidelines. The key experiences and perceptions most commonly discussed by the parents in the focus group sessions were:

- appreciation that the guidelines outlined the postconcussion process that should be followed

- desires for a better understanding of the guidelines by general practitioners (GP) (ie, doctors) who care 
for children with concussion including that they follow and provide advice on the guidelines

- desires to have more information available to parents in a systematic fashion and a more formal policy around timing of return-to-participation following concussion (eg, 2-week mandatory no play period)

- difficulties with the guidelines not addressing delayed presentations of concussion.

These perceptions, particularly those around the level of knowledge and understanding about concussion held by GPs/medical doctors and the associated lack of confidence in the care they provide, reiterate the previously stated need for improved communitybased education and understanding of the best practices around concussion recognition and management among all stakeholders, including the players themselves. ${ }^{7}$ In Australia, GPs typically complete 4 years of undergraduate medical training, followed by an hospital internship and 3-4 years of training to obtain specialist (GP) registration. Their training is general in nature and includes very little sports medicine or concussion-related education.

\section{Club-level implementation}

While this study examined perceptions around the 2011 guidelines, the AFL has updated their guidelines ${ }^{8}$ to address some of the barriers and drivers observed in this study. The new guidelines include parent, player and practitioner information but many parents of communitylevel players may not be aware of these resources. Being directed towards this information, and perhaps even including some of this information in the process of registering to participate in the sport, may improve dissemination. In addition, community clubs and leagues should encourage their local GPs to become familiar with these resources and guidelines. Clubs could also develop partnerships with GPs who do have this knowledge, so that they can recommend or direct parents to visit these specific GPs. While these findings are specific to community AF, other governing bodies across the world have recommended and produced similar guidelines. ${ }^{9} \quad 10$ Therefore, these findings could also improve the development and implementation of concussion guidelines across various sports.

\section{Limitations}

This study is limited by the fact that only two focus groups were conducted. However, saturation of topics raised by the participants was reached and it is not expected that the major findings from this study would have changed if more focus groups had been conducted. Unfortunately, we did not record the profiles of the participants in terms of their gender, age or roles with teams of players, and so on, so it is not possible to describe the specific participants in detail. As noted above, some participants were trained in sports first aid, including concussion recognition and management, and their views may have skewed the results towards them being more aware of concussionrelated issues than other parents. The study was conducted in a male-only AF league, so the views expressed were from parents of boys. Parents of girls may hold different views about concussion guidelines and this should be explored in future research, especially given the increasing popularity of female AF.

\section{CONCLUSIONS}

Parents are key stakeholders in concussion recognition and management in community sport. Important factors to consider when developing and implementing improved concussion guidelines in community sport include increasing their accessibility and visibility for parents and players, addressing delayed presentation of concussion symptoms, explaining how and why to use the guidelines, and developing and enforcing club and league policies that support the use of best practice guidelines when caring for young athletes suffering a concussion.

Acknowledgements The Australian Collaboration for Research into Injury in Sport and its Prevention is one of the International Research Centres for the Prevention of Injury and Protection of Athlete Health supported by the International Olympic Committee. Aspects of this work were undertaken when authors PEW, AD and CFF were previously employed at Monash University.

Contributors PEW and JS designed the focus group schedule. PEW and AD conducted the focus groups. PEW and JRM, with advice from JS, undertook the qualitative coding and analysis of the focus group data. CFF contributed to the design of the larger study that this project was associated with. All authors assisted with the interpretation of the findings. PEW led the writing of the paper and all other authors contributed to its editing and gave their approval of the manuscript for submission.

Competing interests None declared.

Ethics approval Monash University Human Research Ethics Committee (HREC CF12/1178 2012000575).

Provenance and peer review Not commissioned; externally peer reviewed.

Open Access This is an Open Access article distributed in accordance with the Creative Commons Attribution Non Commercial (CC BY-NC 4.0) license, which permits others to distribute, remix, adapt, build upon this work noncommercially, and license their derivative works on different terms, provided the original work is properly cited and the use is non-commercial. See: http:// creativecommons.org/licenses/by-nc/4.0/

(C) Article author(s) (or their employer(s) unless otherwise stated in the text of the article) 2017. All rights reserved. No commercial use is permitted unless otherwise expressly granted.

\section{REFERENCES}

1. Yard EE, Comstock RD. Compliance with return to play guidelines following concussion in US high school athletes, 2005-2008. Brain Inj 2009;23:888-98.

2. Sarmiento K, Mitchko J, Klein C, et al. Evaluation of the centers for disease control and prevention's concussion initiative for high school coaches: "Heads Up: Concussion in High School Sports". J Sch Health 2010;80:112-8.

3. Kemp JL, Newton JD, White PE, et al. Implementation of concussion guidelines in community australian football and rugby League-The experiences and challenges faced by coaches and sports trainers. J Sci Med Sport 2016;19:305-10.

4. Newton JD, White PE, Ewing MT, et al. Intention to use sport concussion guidelines among community-level coaches and sports trainers. J Sci Med Sport 2014;17:469-73. 
5. Hecimovich M, King D, Marais I. Player and parent concussion knowledge and awareness in youth Australian Rules Football. The Sport Journal2016 Available from http://thesportjournal.org/ article/player-and-parent-concussion-knowledge-and-awareness-inyouth-australian-rules-football/. Accessed 9/04/2017.

6. Sandel N, Henry LC, French J, et al. Parent perceptions of their adolescent athlete's Concussion: A Preliminary Retrospective Study. Appl Neuropsychol Child 2015;4:211-6.
7. White PE, Donaldson A, Sullivan SJ, et al. Australian football league concussion guidelines: what do community players think? BMJ Open Sport Exerc Med 2016;2:e000169.

8. AFL Community. Concussion. Accessed 9/04/2017. http://www. aflcommunityclub.com.au/index.php?id=66

9. New Zealand Rugby Concussion. Accessed 9/04/2017.http:// nzrugby.co.nz/rugbysmart/concussion

10. U.S. Soccer. U.S. Soccer concussion guidelines. Accessed 9/04/ 2017. http://www.ussoccer.com/about/recognize-to-recover/ concussion-guidelines 